I have already referred to his plans for an ambulance corps which became the basis for such service in all armies. IIe put an end to the depleting of the ranks of the army which had been caused by injudicious and careless discharges for disability, and by the license of sending to distant general hospitals men who should never have left the zone of operations. IIe insisted on having sick and wounded treated at hospitals nearer the front whenever the condition of the service and the welfare of the patient permitted, thus doing away with one of the chief factors in military alssenteeism. By well-thought-out sanitation, strenuously enforced, he kept the Army of the Potomac in a state of health unparalleled in forces of such magnitude at that time. For alleviating the sufferings and saving the lives of thousands of his countrymen, and for adding to the vigor, discipline and effective fighting strength of the principal army of the Republic, he has a just elaim to the grateful remembrance of his professional brethren, of his comrades in arins, and of his countrymen. General MeClellan wrote of him in 1863, "I never met with his superior in power of organiration and executive ability." His name is now commemorated in the luetterman General Hospital at the Presidio of San Francisco.

'The most distinguished and important internist of the early French school was René Iraennec (1781-1826). Like Bichat, the creator of descriptive anatomy, he was a regimental surgeon in the French Revolution. 33oth were early victims of phthisis. If we can trust Kipling's description it was while a military prisoner in England that Laennec carried out the experiments with the stethescope, the instrument with which his name is indissolubly connected.

Intimately associated with the Post of Plattsburg l3arracks from which I have recently come, is the name of an army medical officer at whose door opportunity knocked and was not refused entrance. Dr. William Beaumont, by his observations and experiments on the Canadian halfbreed, Alexis St. Martin, laid the foundation for our present knowledge of gastric digestion. Part of this work was earricd out at the isolated military post of Mackinaw in the primeval forests of Michigan about 1825, and the remainder of the investigations were conducted at Plattsburg Barracks, N. Y. Beaumont was the true leader and pioneer of experimental physiology in our country. IIis work remains a model of patient, persevering investigation, experiment and research.

The conquest of yellow fever is a far-reaching achievement to which America can lay entire claim and which especially reflects eredit unon the Medical Corps of the United States Army. In 1900 the army board, consisting of Major Walter Reed, Major James Carroll and Contract Surgeons Lazear and Agramonte, proved by a series of brilliant and conclusive experiments that yellow fever is transmitted by the bite of a mosquito, the Stegomyia fasciata. Basing his sanitary work on the diseoveries of Reed and his associates, our present. Surgeon General, William C. Gorgas, freed Cuba of yellow fever and made possible the building of the Panama Canal, thereby establishing his claim to be called the greatest sanitary expert the world has known.

The experiments which established the mosquito theory of yellow fever transmission are so recent and well known, that I shall not enter into them exeept in one particular. Doctor Lazear died from yellow fever contracted while at this work. Actg. Asst. Surg. Robt. P. Cooke and several volunteers from the hospital corps slept for thirty nights in a small unventilated room, using the bedding and wearing the garments just taken from fatal cases of yellow fever, and which were soiled with the black-vomit and exeretions of these patients. Major Carroll first, and subsequently several members of the hospital corps, submitted to the bites of mosquitoes which had previously fed on yellow fever victims. Several of them contracted the diseasc, and Major Carroll narrowly escaped death. The world at large recognizes that it requires high courage for the soldier to charge the enemy, even in the excitement of battle and surrounded by his comrades. In the present European war hundreds of medical men have met wounds and death in serving the cause of fatherland and of humanity under fire. It called for courage of a different quality, but of quite as high an order, to enable a man to submit himself, in cold blood, for experimental infection with a disease which was as mysterious, as painful and as fatal as yellow fever. All honor is due Major Carroll, Dr. Cooke, and those Hospital Corps men who stood this test in the interests of humanity and to the everlasting credit of military medicine. There is no better example of the sentiment that "Peace hath higher tests of manhood than battle ever knew."

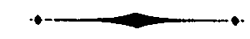

\section{(Briginal Artirlra.}

HCLAMPSIA AT THE BOSTON CITY HOSPITAL: $\triangle$ REVIEW OF THE CASES OF TWTNTY-THREE YEARS.

By Innest Boyen Yoling, M.I., Bohton,

Junior Visiting Surgen for Discases of Women, Boston City Ilospital; Assistant Surgeon, Massachusetts Women's IIospital; Instructor in Gynecology, IIarvard Medical School.

During the past twenty-three years, 183 women with threatened or actual eclampsia have been admitted to the Gynecological Service at the Boston City Hospital. Thirty-six of these 
were admitted post-partum, having been deliv- not always been the fault of those who wrote ered outside the hospital, either normally or by them, for many patients have entered unconoperative procedures concerning which little or scious, and still others have had neither the innothing is known. The same applies to the de- telligence nor command of English to enable tails concerning the children. A few women them to respond to the questions.

( 6 in number) were received early, as threat- The character of the cases upon which this ened eclamptics, and, after treatment, left the paper is based may be judged from the fact that hospital undelivered; while 14 others, entering 146 had convulsions, most often multiple; 20 with mild symptoms, miscarried or were event- apparently had none; and in 17 there was no

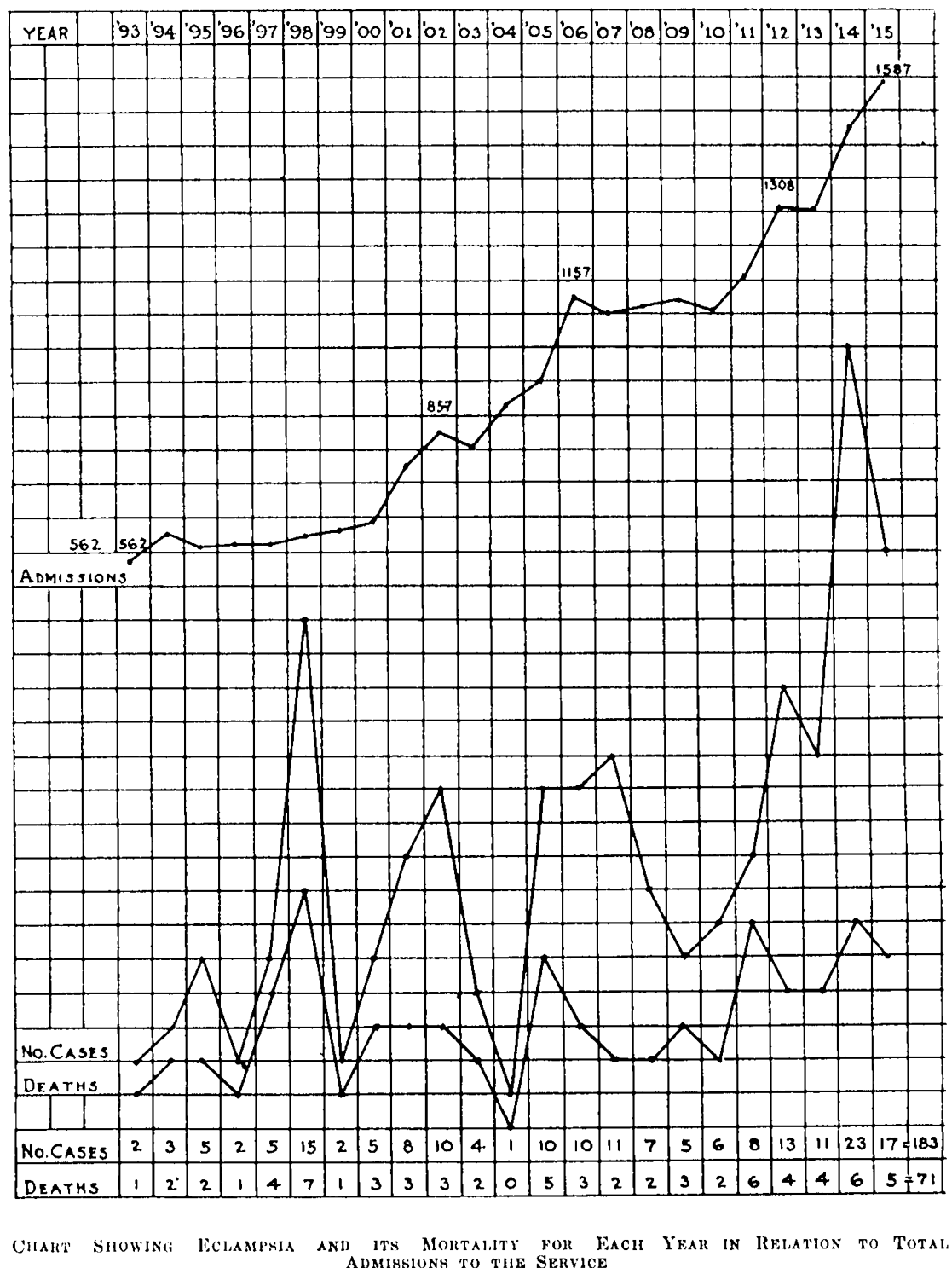

nally delivered. Deducting the 20 milder/information available; although in a great proeases, the remaining 163 cases, which include 36 portion of this last group, it is probable that received post-partum, entered usually as emer- they occurred. In this paper the writer has atgencies, often unconscious, and after convul- tempted to give the facts, in so far as possible, sions had occurred. The majority, if we may concerning the eclamptic emergencies admitted judge from the records, were in very critical to the Baston City Hospital, which may be condition at the time of admission, and some classed in the main as neglected cases.

were moribund.

A review of the nationalities has failed to be

The facts in the records, while interesting, are of much value. Data as to birth were available exceedingly hard to classify, and disappointing in exactly 140 cases, and of these 29 were born in many ways, owing to the incomplete informa- in Ireland and 63 in the United States. In spite fion they contain. This, it is fair to state, has of the large number of Jewish patients treated 
in the wards, they number only 10 in the series, and appear to possess a great resistance to the toxemias of pregnancy, as they certainly do to pucrperal infection.

$\Lambda$ comparison of the annual number of admissions to the service during these 23 years with the number of eclamptics (threatened or actual) during the same period, shows that the incidence is irregular, and that the number treated does not correspond with increase in patients. 'l'he time of year does not seem to have any particular bearing, for although the greatest number entered in January (20), the cases are quite evenly distributed through the rest of the year.

The age in 140 patients, where this was known, was :

$$
\begin{aligned}
& 15-20 \text { years } \ldots \ldots \ldots \ldots \ldots .28
\end{aligned}
$$

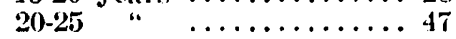

$$
\begin{aligned}
& 25-30 \quad \text { " } \quad \ldots \ldots \ldots \ldots \ldots \ldots 27 \\
& \text { 30-35 “ } \quad \ldots \ldots \ldots \ldots \ldots \ldots 17 \\
& 35-40 \text { " } 3 \ldots \ldots \ldots \ldots \ldots 13 \\
& 40-45 \text { “ } \quad \ldots \ldots \ldots \ldots \ldots \ldots \text { 6 } \\
& 45-50 \text { " } \ldots \ldots \ldots \ldots \ldots .2 \\
& 140
\end{aligned}
$$

In 138 cases in which the number of the pregnancy was available, 90 were primiparae; 16 were pregnant for the second time; and in 30 the pregnancy varied quite evenly from the third to the twelfth. There was one in the fourteenth and one in the twentieth pregnancy (15 full term, 4 miscarriages). In addition to these, but not included above, were 6 " multiparae" in whom the number of pregnancies was not stated.

The month of the pregnancy, as given, was often approximate, but the statistics in 167 cases are as follows:

$$
\begin{aligned}
& \text { 5. } 6 \text { months } \ldots \ldots \ldots \ldots \ldots, 10 \\
& \text { 6. } 7 \text { " } \\
& \text { 7-8 " } \quad \text { "........... } 51 \\
& \text { 8- } 9 \quad \text { " } \quad \ldots \ldots \ldots \ldots \ldots \ldots \ldots \ldots \ldots \\
& 9-10 \text { ، } \quad \ldots \ldots \ldots \ldots \ldots \ldots \ldots \ldots \\
& 167
\end{aligned}
$$

The statements as to duration of symptoms before entrance are of comparatively little value, and vary in time from "a few hours" to eight weeks. The symptoms of which the patients complained were those common to this form of toxacmia of pregnancy.

Three cases are recorded in which there had been eclamptic seizures during a previous pregnancy. One of these patients, then in her eighth pregnancy, had convulsions in the pregnancy preceding, and the remaining two, both in their fifth pregnancy, had each a similar attack; one woman with her first and the other with her third child. Three of the severe cases were too near death to deliver.

All the urinary examinations showed albumen, with one exception, and in this instance the patient recovered. Jaundice is mentioned but once and this patient died on the seventh day.
Convulsions were stated to bave occurred in 146 of the 166 eases with available information on this point. 'This includes all admitted to the wards, before and alter delivery. The seizures were multiple in most instances and the condition of some, not included because details were wanting, would indicate that convulsions had taken place before admission.

'The following table gives the statisties of $\mathbf{1 6 6}$ cases with reference to eonvulsions:

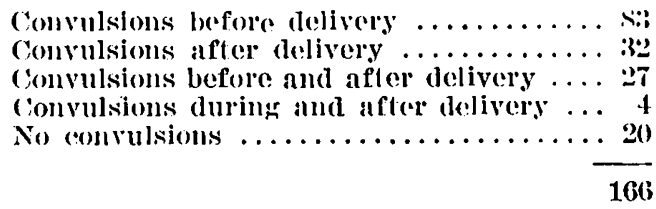

Although 20 had no convulsions, 14 of these were lelivered because of "threatened eclampsia" or delivered themselves by spontaneous abortion. Six were discharged undelivered.

'The mortality of the series is appalling, but considering the ciremnstances, it is surprising that the results are even as good. In the first place, it must be remembered that a great number of these women were examined outside the hospital; that most had received no treatment, and that some were even found by chance-as one woman lying in the bottom of a closet; another comatose in bed with a foctus beside her, which had been born during the eonvulsions. Many have been received moribund or in a condition offering little hope of benefit from any procedure.

The deaths compared with the admissions appear in the chart, so it will suffice to say that of 183 cases, including all those admitted to the

\begin{tabular}{|c|c|c|c|}
\hline & & Mecovento & Dimn \\
\hline Forceps & 24 & 19 & \\
\hline Version & (i.4 & 29 & 35 \\
\hline Non-operntive dolivery & 37 & ?ר & 8 \\
\hline Vaginal Cacsareau .... & 4 & 1 & 3 \\
\hline Abdominal Caesarean & 1 & 1. & 0 \\
\hline DOHA & & 79 & 51 \\
\hline
\end{tabular}
wards at any stage, 112 recovered from the toxaemia and 71 died-2 of the latter from sepsis after some weeks of sickness. Three were ton far gone to deliver. Of the 36 women admitted post-partum, and included in the figures above, 23 lived and 13 died. Many of these were apparently delivered normally at full term, and, having convulsions, were sent to the hospital.

In 130 cases, including 3 delivered outside the hospital, the results for the mothers, delivered by various methods, were as follows:

Manual dilatation was employed in many of the severe eases. Of 49 cases where the cervix was opened by this method, without using the Voorhees bag, 31 recovered and 18 died.

There were also five cases where multiple incisions of the cervix were tried,-apparently in combination with some form of dilatation,-and of these. 1 survived and 4 died.

The Voorhees bag was used in 22 cases. Four 
non-operative deliveries recovered, one of which had a blood pressure of 210 at the time of admission, and 3 died.

Of 15 operative deliveries 3 died, 2 of these after use of the bag at the start, with blood pressures of 210 and 220 respectively. 'Twelve recovered,- -one with a blood pressure of 190 . Fourteen of the 15 operative cases were delivered with forceps or by version, and in one the method of delivery was not stated. In two, the dilatation of the cervix was completed manually.

The number of the convulsions and the time of their occurrence are unobtainable in many cases, owing to the manner in which the cases are received-often with no history. In the series of 166 cases previously considered, of 83 women, with convulsions before delivery, 29 died; of 32 , with convulsions after delivery, 10 died; of 27 with convulsions before and after delivery, 13 died ( 1 sepsis); and of 4 with convulsions during and after delivery, 3 died ( 1 sepsis). There were 20 cases with no convulsions and a mortality of 3.

The mortality among the 146 women with convulsions at some time during the toxaemia was 55 ; two dying of sepsis.

As would be expected, the longer the convulsions continued, the more deep the toxaemia and the worse the prognosis.

Figures concerning the mortality of the children are unsatisfactory. Many of our patients do not know the duration of their pregnancy, and often no data can be obtained. Thus many of the ages given were simply approximate and the figures, for living children, represent only those who apparently left the hospital alive.

Considering a seven months child as viable, in 125 deliveries there were 99 viable children (2 pairs twins), 33 of whom survived. Of 31 viable children born ly normal labor, 21 died; while in 67 labors, 68 children (1 pair twins) were delivered by operative means, with a mortality of 52 . There seems to be comparatively little difference in outcome between operative and normal deliveries as far as the child is concerned. This is undoubtedly due to the fact that many of the babies were premature, and their mothers extremely toxic. On the other hand, the eases where low forceps were used are included and would tend to help out the operative record.

The results of operative and non-operative treatment on both mothers and children have been considered. In looking over the records, the writer often finds it diffieult to differentiate between mothers dying of toxaemia and those already weakened who perished from the shock of delivery. The number of convulsions, pulse rate and blood pressure are not by any means infallible guides as to how an eclamptic will bear nperative delivery, and the writer, watehing the results of the various methods, has changed his opinions somewhat regarding im- mediate delivery by heroic measures. Many apparently hopeless cases survive a long operative delivery; and some, in apparently the same endition, fail to recover after very simple procedures. Under all cireumstances the shock of an operative delivery is eonsiderable, although many of those so delivered would doubtless perish under any for'm of treatment. It is usually in the milder eases that more gentle and prolonged methods of delivery are apt to be employed, although they appear, from the experience of the writer, equally effective, if not more necessary, in many of the severe cases under discussion.

Owing to the serious condition of most of these patients, the milder, rather than the more immediate and strenuous methods seem better suited for their delivery, and the latter should be used only when the former appear inadequate. Some patients may possibly be lost by delay, but more will be saved by the avoidance of shock.

In primiparae (except in the very early months) both where labor has not begun and where there is partial dilatation and a rigid os, most serious cases may be delivered by the use of the dilating bags; while in multiparae they are often still more effective. By this means we are imitating the processes of nature by which the best results in delivery appear to be attained.

Whether the irritation of the bag in the utcrus tends to continue or to excite convulsions is a question upon which the writer is as yet undecided. Most excellent results have been obtained by their use in desperate cases, and there have been unfavorable results as well.

Although delivery is lengthened in some, there is much less shock, less liability to laceration of the cervix, and less chance of sepsis, even though manual dilatation is used to complete the task. A rigid os frequently softens and manual dilatation, if necessary, is more readily accomplished. The fact should be pointed out that Voorhees bags alone were used in some cases too sick for operative delivery.

For the vaginal Caesarean section as a means of immediate delivery, the writer sees no advantage in the clean cases advanced beyond 6 months; since the operation is difficult in primiparae under any circumstances. In multiparae it is also difficult, if the cervix is high in the pelvis. $\Lambda$ fter the uterus is opened, the labor must still be ended by forecps or version and the repair is long and tedious. There were but 4 eases in this series, 3 of which were operated in extremis and fatal; one lying on the table. Abdominal Cacsarean section has been performed once. The writer believes it proper in certain cases where immediate delivery appears necessary and other methods seem too prolonged, uncertain and difficult, because of the size of the child or the condition of the cervix.

The relation of blood pressure to prognosis 
and treatment is a matter of great interest in the severe types; but the available data are too small for absolute conclusions. Of 42 cases with data available, 12 died. 'Three died out of 7 with a pressure of 200 or over; 9 others died with pressures varying from 104 to 160 ; while 30 cases, varying from 210 to 706 and with an average systolic pressure of 157 , all recovered.

The methods of delivery were so dissimilar that no comparison could be made to show the influence of any special method of delivery upon results.

High blood pressure makes the outlook less hopeful, but does not necessarily mean a fatal outcome. Diminution of pressure after delivery is a hopeful sign.

The number of venesections is too small for reliable statisties, especially concerning a procedure where judgment as to worth depends so much on an intimate knowledge of the individual case. It has been tried in the eases with high pressure and usually in severe types after delivery.

There were 18 venesections, 9 of whom recovered and 9 dicd. Six of the 9 mortalities were in cases received post-partum, and two of those who recovered were likewise admitted after labor. One patient died undelivered.

In ante-partum venesection, the writer has little faith, except in certain plethoric individuals, and believes it should be employed with the greatest care at this stage. It is not possible to foretell either the amount of blood which will be lost during birth or the reaction of a toxaemic patient to the strain of delivery.

Venesection is often of great advantage in the strong, healthy, full-blooded, restless individual, where blood pressure remains high or has a tendeney to rise after delivery; but in those who are frail or fat and flabby its advantages are very doubtful. Loss of blood lowers the resistance to infection, to which all cases of toxaemia of pregnancy are very susceptible.

During bleeding the blood pressure should be carefully watched and not allowed to fall below normal; while to all cases of venesection, fluid should be administered either by rectum or by hypodermoclysis where the first method is not available. Additional fluid is not required by patients with oedema of the tissues.

The medical treatment has been along the usual lines,--free catharsis, gastric lavage, control of convulsions by sedatives and ether, enteroclysis, hypodermoclysis, and hot packs in some cases. Sweating has not been used so often during the latter years. It has appeared to be of doubtful efficacy, and distinctly detrimental to some.

The fact that patients, too sick for safe operative delivery, sometimes recover under medical treatment is often forgotten in the desire to obtain immediate results. The Voorhees bag may be advantageously combined with medical treatment. There are a number of cases in the pres- ent series where delay in obstetric surgery has been followed by recovery, when operative measures would have been fatal for the mother. Each case must be considered by itself and no general rule ean be applied; except that the method adopted for delivery should be the gentlest and most efficacious for that individual.

Hrom what has gone before, it is clear that results with the class of cases received in our wards camnot be as good as one would wish, but are about what might be expected. On the whole, the mortality seems to be lessening. Unfortunately this cannot be ascribed to treatment alone, as the severity of eclampsia varies in different years.

This series is published in the hope that it may aid in some larger collection of cases.

'The conclusions reached have been deduced from a study of the cases and are not all capable of proof by statistics alone.

CONCIJISIONS.

1. Incidence varies greatly in different years and without apparent cause.

2. Severe attacks occur mostly in primiparae from 20-25 years, in the latter half of pregnancy.

3. A little over one-half the cases with convulsions have seizures after delivery.

4. Non-operative delivery is most favorable for the mother.

5. The longer the convulsions continue, the greater the mortality.

6. Child mortality is high whether deliveries are operative or non-operative, owing to prematurity and toxaemia.

7. High blood pressure increases the gravity of the prognosis.

8. Venesection is a useful procedure in cases with high pressure and restlessness after delivery.

9. Induction of labor and delivery with the least possible operative interference offers the best ehance of recovery for the mother.

10. Caesarcan section is justified in certain cases where delivery by other methods seems too prolonged or doubtful in outeome.

REMISSIONS IN LEUKEMIA PRODUCED BY RADIUM IN CASES COMPIJETELY RESISTANT TO X-RAY AND BEN7OT, TREATMENT.**

By Tiromas Ordway, M.I., Amany, N. Y., Associate Professor of Merlicine, Albany Medical Collegr.

Tuose who have had extensive personal experience with and opportunity for intensive 916. 